\title{
Micronutrient intake and adequacy in women of child-bearing age (WCBA) (18-50y) in Ireland
}

There is an increasing recognition that women's pre-conceptual health (including nutritional status) sets the foundation for a successful pregnancy and the subsequent lifelong health of the baby. Almost half of pregnancies in Ireland are unplanned and dietary recommendations for women of child-bearing age (WCBA) are not differentiated by pregnancy intention. A daily $400 \mu \mathrm{g}$ folic acid supplement is recommended for all WCBA to reduce the risk of neural tube defect in an occurring pregnancy ${ }^{(1)}$. The objective of this study was to estimate micronutrient intake, adequacy of intake and compliance with the folic acid supplement recommendation in WCBA (18-50y) in Ireland. Analyses were based on the National Adult Nutrition Survey (NANS) (2008-2010) (www.iuna.net). A 4 day semi-weighed food record was used to collect food and beverage intake data (including nutritional supplement use) from a nationally representative sample of 1500 adults (487 women (18-50y)). Nutrient analyses were carried out using UK ${ }^{(2)}$ and Irish $^{(3)}$ food composition data. Usual intakes of nutrients were calculated via the NCI-method using SAS ${ }^{\mathcal{C}}$ Enterprise Guide ${ }^{(4)}$. Adequacy of micronutrient intake was assessed using the most recently published estimated average requirements (EAR) from the European Food Safety Authority (EFSA) ${ }^{(5)}$ or the UK Department of Health ${ }^{(6)}$ and the Institute of Medicine's EAR in the case of vitamin $\mathrm{D}$ and iodine ${ }^{(7,8)}$. Under-reporters ( $32 \%$ of sample), defined using minimum energy intake cut-off points, calculated as multiples of BMR were excluded from analyses.

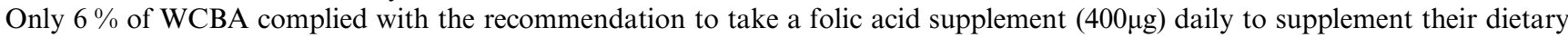
folate intake. Furthermore, a significant proportion of women of child-bearing age had inadequate intakes of important nutrients including vitamins A, D \& C, riboflavin, dietary folate equivalents, calcium and iodine. Strategies to increase micronutrient intakes and improve compliance with the folic acid supplement recommendation are needed to improve pre-conceptual health status for women of WCBA in Ireland.

The National Adult Nutrition Survey was funded by the Irish Department of Agriculture, Fisheries \& Food under the Food for Health Research Initiative (2007-2012).

Table 1. Usual micronutrient intakes in women of childbearing age and the proportion of women with micronutrient intakes below the estimated average requirement (EAR) excluding under-reporters ( $n$ 335)

\begin{tabular}{|c|c|c|c|c|c|}
\hline Micronutrients & Mean & SD & Median & EAR & $\%<$ EAR \\
\hline Vitamin D $(\mu \mathrm{g})$ & 4.0 & 0.3 & 3.3 & $10 \mu \mathrm{g} / \mathrm{d}$ & 95.9 \\
\hline Vitamin C (mg) & 118 & 9.6 & 91.9 & $80 \mathrm{mg} / \mathrm{d}$ & 43.1 \\
\hline Dietary folate equivalents $(\mu \mathrm{g})$ & 391 & 21.8 & 342 & $250 \mu \mathrm{g} / \mathrm{d}$ & 27.9 \\
\hline Riboflavin (mg) & 2.4 & 0.2 & 2.0 & $1.3 \mathrm{mg} / \mathrm{d}$ & 23.4 \\
\hline Vitamin A $(\mu \mathrm{g})$ & 999 & 51.4 & 901 & $490 \mu \mathrm{g} / \mathrm{d}$ & 13.2 \\
\hline Vitamin B6 (mg) & 3.2 & 0.2 & 2.7 & $1.3 \mathrm{mg} / \mathrm{d}$ & 9.0 \\
\hline Vitamin B12 $(\mu \mathrm{g})$ & 5.4 & 0.4 & 4.5 & $1.25 \mu \mathrm{g} / \mathrm{d}$ & 3.6 \\
\hline Thiamin $(\mathrm{mg})$ & 1.2 & 0.1 & 10.6 & $0.3 \mathrm{mg} / 1000 \mathrm{kcal}$ & 1.5 \\
\hline Niacin (mg) & 21.7 & 0.6 & 20.9 & $5.5 \mathrm{mg} \mathrm{NE} / 1000 \mathrm{kcal}$ & 0.0 \\
\hline Calcium (mg) & 891 & 31.0 & 854 & $750 \mathrm{mg} / \mathrm{d}$ & 35.7 \\
\hline Iodine $(\mu \mathrm{g})$ & 149 & 7.2 & 137 & $95 \mu \mathrm{g} / \mathrm{d}$ & 23.5 \\
\hline Iron (mg) & 13.5 & 0.6 & 12.2 & $7 \mathrm{mg} / \mathrm{d}$ & 5.9 \\
\hline
\end{tabular}

1. Food Safety Authority of Ireland (2011) Dublin: The Food Safety Authority.

2. Food Standards Agency (2002) Cambridge: Royal Society of Chemistry.

3. Black LJ, Ireland J, Møller A et al. (2011) J Food Comp Anal 24, 1017-1023.

4. Tooze JA, Kipnis V, Buckman DW et al. (2010) Stat Med. 29 (27): 2857-68.

5. EFSA (2017) EFSA J 14 (12): e15121E.

6. UK Department of Health (1991). London: HMSO

7. Institute of Medicine (2011) Washington, DC: The National Academies Press.

8. Institute of Medicine (2011) Washington, DC: The National Academies Press. 